\title{
Number of Electroconvulsive Therapy Sessions required for Thai Psychiatric Patients: a Retrospective Study
}

This article was published in the following Dove Press journal: Neuropsychiatric Disease and Treatment

\author{
Pichai Ittasakul' \\ Siraprapha Vora-arporn (iD) \\ Punjaporn Waleeprakhon' \\ Phern-Chern Tor ${ }^{2}$ \\ 'Department of Psychiatry, Faculty of \\ Medicine, Ramathibodi Hospital, Mahidol \\ University, Bangkok, Thailand; ${ }^{2}$ Department \\ of Mood and Anxiety, Institute of Mental \\ Health, Singapore
}

Objective: To study predictors of the number of electroconvulsive therapy (ECT) sessions required for symptom remission in psychiatric patients.

Patients and Methods: We conducted chart reviews for 95 patients whose condition remitted following inpatient ECT. We analyzed the clinical characteristics of the patients and compared the number of ECT sessions between adult (age 18-59 years) and elderly (age $\geq 60$ years) patients.

Results: The overall mean \pm SD of the number of ECT sessions was $11.8 \pm 4.7$ (range: 6-24). By diagnosis, it was $13.3 \pm 5.5$ for individuals with schizophrenia, $10.1 \pm 2.7$ for schizoaffective disorder, $14.4 \pm 5.6$ for bipolar depression, $9.4 \pm 1.9$ for bipolar mania, $10.9 \pm$ 4.3 for major depressive disorder (MDD), and 11.8 \pm 4.3 for those with other diagnoses. For MDD, the number of ECT sessions in elderly patients $(13.4 \pm 4.6)$ was statistically greater than that in adult patients $(9 \pm 2.9)(\mathrm{p}=0.008)$.

Conclusion: The number of ECT sessions varied by age and diagnosis. The number of ECT sessions in elderly MDD patients was higher than that in adult MDD patients.

Keywords: ECT, treatment, Thai patients, major depressive disorder, elderly

\section{Introduction}

Electroconvulsive therapy (ECT) has been used to treat psychiatric conditions since the 1940s. ECT is beneficial for patients who require a rapid treatment response and have not responded adequately to pharmacotherapy. For acute treatment, a typical ECT course involves 6-12 treatments. ${ }^{1-3}$ ECT is usually stopped when patients achieve remission or the clinical effect plateaus (ie, no additional benefits are observed for two or three successive ECT sessions). When remission is achieved, maintenance ECT is suggested for some patients to prevent the relapse of psychiatric symptoms.

The number of acute ECT treatments applied is highly variable in different settings, ${ }^{4}$ and should be determined according to the severity of illness and benefits and risks of treatment. ${ }^{2}$ Previous studies have indicated that psychiatric diagnosis, sex, age of onset, number of illness episodes, and changes in symptoms during ECT all contribute to this variability. ${ }^{5-8}$ A retrospective study of patients with treatmentresistant schizophrenia who received ECT with clozapine found that the mean number of treatments was 14 (range: $5-45$ ). ${ }^{9}$ With respect to mood disorders, a previous study of hospitalized patients who received ECT found that the mean number of treatments needed to achieve remission in patients with bipolar depression (7.5) was lower than that in patients with unipolar depression (10.2). ${ }^{5}$ Pitidhammabhorn et al reported that
Correspondence: Pichai Ittasakul

270 Rama VI Road, Ratchathewi, Bangkok 10400, Thailand

Tel $+662-20$ I 1478

Fax +662-200-3277

Email pichai.itt@mahidol.edu 
psychiatric inpatients received a mean of 8.6 ECT sessions (range: 1-24), and that the number of treatment sessions was similar across psychiatric diagnoses. ${ }^{10}$

To our knowledge, few studies have examined the number of ECT sessions and associated factors in Thai psychiatric patients. In Thailand, most psychiatrists tend to prescribe ECT as a last resort for patients who do not respond to other treatment modalities. Knowledge about ECT is helpful for clinicians when estimating the number of ECT sessions a patient may undergo and for informing patients and their caregivers regarding the estimated duration of ECT treatment. In the current study, we examined predictors of the number of ECT sessions required for symptom remission in psychiatric patients.

\section{Patients and Methods}

\section{Setting and Study Design}

The study protocol was approved by the Ethics Committee on Human Experimentation of the Faculty of Medicine, Ramathibodi Hospital, Mahidol University, Bangkok, Thailand. Written informed consent was obtained from patients or their families. Research was conducted in accordance with the Declaration of Helsinki.

The study design was retrospective. We conducted chart reviews for all patients who received inpatient ECT from January 2013 to November 2018 at the institution. Psychiatric diagnoses were performed by psychiatrists based on the DSM-IV-TR ${ }^{11}$ criteria. Patients who discontinued ECT owing to any reasons other than the achievement of remission were excluded from the study. We collected demographic data, as well as information regarding clinical characteristics, physical and mental illness, and ECT data (eg, indications, stimulus dose, electrode placement method, and number of sessions). Psychiatric rating scales, including the Brief Psychiatric Rating Scale $(\mathrm{BPRS})^{12,13}$ for schizophrenia, Montgomery Asberg Depression Rating Scale (MADRS) ${ }^{14,15}$ for depression, and Young Mania Rating Scale (YMRS) ${ }^{16,17}$ for mania, were used to assess the severity of symptoms at baseline ( $24 \mathrm{hrs}$ before ECT), after every 3 sessions of ECT treatment, and after the last ECT session. The BPRS is an 18item rating scale frequently used to assess the severity of symptoms in patients with schizophrenia. Each item is rated on a scale from 1 (symptom is not present) to 7 (extremely severe). ${ }^{13}$ The MADRS is a 10 -item rating scale used to assess the severity of depressive symptoms. ${ }^{15}$ Each item is scored from 0 to 6 . The YMRS is an 11-item rating scale used to assess the severity of manic symptoms ${ }^{17}$ Each item is scored from 0 to 4 . Assessments were performed by staff and psychiatric residents who had received appropriate training. Assessments of inter-rater reliability were performed using the Intraclass Correlation Coefficient (ICC). The ICC was 0.99. Remission was defined as follows: BPRS $<31$ for schizophrenia, ${ }^{12}$ MADRS $<10$ for depression, ${ }^{14}$ and YMRS $<10$ for mania. ${ }^{16,17}$

\section{ECT Treatment}

All patients were assessed by psychiatrists and anesthesiologists before receiving ECT. Benzodiazepines were discontinued at least $15 \mathrm{hrs}$ before treatment. The ECT procedures were performed at the post-anesthetic care unit (PACU) by the ECT team, which included psychiatric staff, psychiatric residents, anesthetic staff, psychiatric nurses, and anesthetic nurses. After administration of thiopental (1-6 mg/kg IV) or propofol (1-2 $\mathrm{mg} / \mathrm{kg} \mathrm{IV}$ ) for anesthesia and succinylcholine $(0.5-1 \mathrm{mg} / \mathrm{kg} \mathrm{IV})$, which is a muscle relaxant, ECT was conducted using a modified technique involving a brief pulse wave generated by a Mecta Spectrum 5000Q (Mecta Corp, USA) or Thymatron ${ }^{\circledR}$ System IV. ECT was performed three times per week.

The electrode placement was determined by the psychiatrists who prescribed ECT. The seizure threshold (ST) was determined at the first ECT session by empirically derived stimulus titration. The stimulus intensity was then increased to $500 \%$ above the ST for right unilateral (RUL) electrode placement and 50\% above the ST for bilateral (BL) electrode placement. ${ }^{18}$ Treatment was typically stopped when maximal improvement was reached or when adverse effects limited further treatments. For analysis in this study, we included the number of ECT sessions from baseline until patients reached remission.

\section{Statistical Analysis}

We divided patients into a younger group (age 18-59 years) and an older group (age $\geq 60$ years). We analyzed the clinical characteristics of the patients and compared the number of ECT sessions between adult and elderly patients. All statistical analysis was performed using SPSS 21.0 for Windows (IBM Corp., Armonk, NY, USA). Data were presented using the mean \pm standard deviation (SD) and percentages for continuous and categorical outcomes, respectively. We assessed the data distribution to determine the appropriate statistical test. Continuous measures were compared using independent $t$-tests and a one-way ANOVA, as indicated. Categorical 
parameters were compared using chi-squared and Fisher's exact tests, as indicated. Statistical significance was set such that the $\mathrm{P}$-value $<0.05$.

\section{Results}

\section{Demographic Characteristics}

One hundred and nineteen inpatients had received ECT treatment. Of this group, 95 patients (78\%) achieved remission following ECT treatment. The clinical characteristics of the 95 patients are shown in Table 1. The group ranged in age from 18 to 81 years. We divided them into a younger group (18-59 years) and an older group (60-81 years). Approximately, 20\% (19/95) of the patients were elderly (age $\geq 60$ years). The most common diagnoses were schizophrenia (32/95, 33.7\%), major depressive disorder (MDD) (25/95, 26.3\%), and bipolar mania (14/95, 14.7\%).

\section{Number of ECT Sessions}

The average overall number of ECT sessions was $11.8 \pm$ 4.7 , with a range of 6-24. The number of ECT sessions varied by diagnosis (Table 2). We found no significant

Table I Demographic Data (Total $\mathrm{N}=95)$

\begin{tabular}{|l|l|}
\hline Characteristics & N (\%) or Mean \pm SD \\
\hline Female (\%) & $60(63.2 \%)$ \\
\hline Age (years) & $46.1 \pm 15.7$ \\
$\quad$ <0 years & $76(80 \%)$ \\
\hline 60 years & $19(20 \%)$ \\
\hline Body mass index & $25.1 \pm 5.8$ \\
\hline Diagnosis & \\
Schizophrenia & $32(33.7 \%)$ \\
Schizoaffective disorder & $10(10.5 \%)$ \\
Bipolar disorder & $24(25.3 \%)$ \\
Major depressive disorder & $25(26.3 \%)$ \\
Other diagnosis & $4(4.2 \%)$ \\
\hline Duration of illness & $12.4 \pm 9(12.9)$ \\
History of previous ECT & $25(26.3 \%)$ \\
\hline Concurrent medication & \\
Benzodiazepine & $4(4.2 \%)$ \\
Antipsychotic & $82(86.3 \%)$ \\
Antidepressant & $22(23.2 \%)$ \\
Anticonvulsant & $6(6.3 \%)$ \\
Anticholinergic & $12(12.6 \%)$ \\
\hline Electrode placement & $32(33.7 \%)$ \\
Right unilateral & $63(66.3 \%)$ \\
Bilateral & \\
\hline
\end{tabular}

Abbreviations: SD, standard deviation; ECT, electroconvulsive therapy.
Table 2 Number of ECT Sessions

\begin{tabular}{|c|c|c|c|}
\hline Clinical Characteristics & $\mathbf{N}$ & $\begin{array}{l}\text { Mean } \pm \text { SD } \\
\text { Number of } \\
\text { ECT } \\
\text { Sessions }\end{array}$ & P value \\
\hline \multicolumn{4}{|l|}{ Sex } \\
\hline Female & 60 & $11.8 \pm 4.9$ & 0.942 \\
\hline Male & 35 & $11.7 \pm 4.6$ & \\
\hline \multicolumn{4}{|l|}{ Age } \\
\hline$<60$ years & 76 & $11.2 \pm 4.6$ & $0.014^{*}$ \\
\hline$\geq 60$ years & 19 & $14.2 \pm 4.7$ & \\
\hline \multicolumn{4}{|l|}{ Diagnosis } \\
\hline Schizophrenia & 32 & $13.3 \pm 5.5$ & 0.263 \\
\hline Schizoaffective disorder & 10 & $10.1 \pm 2.7$ & \\
\hline Bipolar disorder & 24 & & \\
\hline - Depression & 10 & $14.4 \pm 5.6$ & \\
\hline - Mania & 14 & $9.4 \pm 1.9$ & \\
\hline Major depressive disorder & 25 & $10.9 \pm 4.3$ & \\
\hline Other diagnosis & 4 & $11.8 \pm 4.3$ & \\
\hline \multicolumn{4}{|l|}{ Body Mass Index (BMI) } \\
\hline Underweight $(<18.5)$ & 11 & $12 \pm 6$ & 0.998 \\
\hline Normal (I8.5-25) & 40 & $11.8 \pm 4.2$ & \\
\hline Overweight (25-30) & 30 & $11.8 \pm 5.1$ & \\
\hline Obese $(>30)$ & 14 & $11.6 \pm 4.9$ & \\
\hline \multicolumn{4}{|l|}{ History of Previous ECT } \\
\hline No & 70 & $11.6 \pm 4.5$ & 0.427 \\
\hline Yes & 25 & $12.4 \pm 5.4$ & \\
\hline \multicolumn{4}{|l|}{ Concurrent Medication } \\
\hline Benzodiazepine & & & 0.103 \\
\hline No & 91 & $12 \pm 4.8$ & \\
\hline Yes & 4 & $8 \pm 1.4$ & \\
\hline Antipsychotic & & & 0.937 \\
\hline No & 13 & $11.7 \pm 4.9$ & \\
\hline Yes & 82 & $11.8 \pm 4.7$ & \\
\hline \multicolumn{4}{|l|}{ Antidepressant } \\
\hline No & 73 & $11.7 \pm 4.8$ & 0.853 \\
\hline Yes & 82 & $12 \pm 4.6$ & \\
\hline \multicolumn{4}{|l|}{ Anticonvulsant } \\
\hline No & 89 & $11.7 \pm 4.7$ & 0.413 \\
\hline Yes & 6 & $13.3 \pm 5.4$ & \\
\hline \multicolumn{4}{|l|}{ Anticholinergic } \\
\hline No & 83 & $11.9 \pm 4.8$ & 0.629 \\
\hline Yes & 12 & $11.2 \pm 4.7$ & \\
\hline \multicolumn{4}{|l|}{ Electrode Placement } \\
\hline Right unilateral & 32 & $1 \mathrm{I} .8 \pm 4.3$ & 0.973 \\
\hline Bilateral & 63 & $11.8 \pm 5$ & \\
\hline
\end{tabular}

Note: $*_{p}<0.05$

Abbreviation: SD, standard deviation.

differences in the number of ECT sessions by sex, history of previous ECT, concurrent medication in the $24 \mathrm{hrs}$ before ECT, or electrode placement (Table 2). The mean 
\pm SD number of ECT treatments in elderly patients (14.2 \pm 4.7) was statistically higher than that in adult patients (11.2 $\pm 4.6)(\mathrm{t}=-0.3, d f=93, \mathrm{p}=0.014)$.

\section{Number of ECT Treatments in Elderly versus Adult Patients}

We compared the clinical characteristics of the elderly and adult patients (Table 3 ). The proportion of elderly patients with MDD (11/19, 57.9\%) was significantly greater than that of the adult patients $(14 / 76,18.4 \%)$ (Chi-square $=$ $12.2, d f=1, \mathrm{p}=0.0047)$. The proportion of elderly patients who received RUL electrode placement (11/19, 57.9\%) was greater than that of adult patients $(21 / 76,27.6 \%)$ (Chisquare $=6.2, d f=1, \mathrm{p}=0.013$ ).

Table 3 Clinical Characteristics of Elderly and Adult Patients

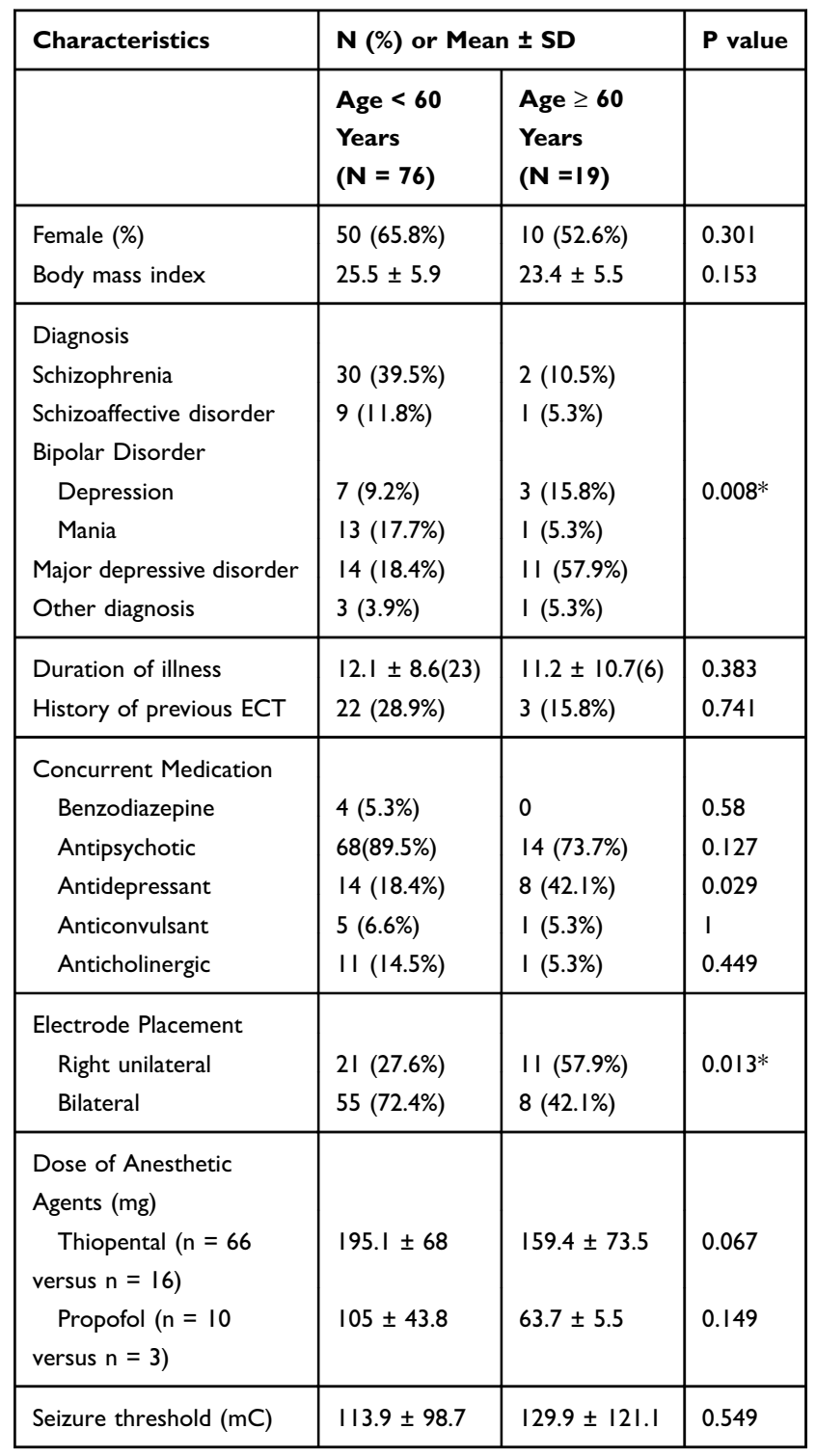

Note: ${ }^{*} p<0.05$

Abbreviations: SD, standard deviation; mg, milligrams; mC, millicoulombs.
In the elderly group, the mean $\pm \mathrm{SD}$ number of ECT sessions was 14 for those with schizophrenia $(\mathrm{n}=2), 13$ for schizoaffective disorder $(\mathrm{n}=1), 9$ for bipolar mania ( $\mathrm{n}$ $=1), 19.3 \pm 5.7$ for bipolar depression $(\mathrm{n}=3), 13.4 \pm 4.6$ for major depressive disorder $(\mathrm{n}=11)$, and 14 for other diagnoses $(\mathrm{n}=1)(\mathrm{F}=1.1, \mathrm{p}=0.419)$.

In the adult group, the number of ECT sessions was $13.2 \pm 5.7$ for those with schizophrenia $(n=30), 9.8 \pm 2.6$ for schizoaffective disorder $(\mathrm{n}=9), 9.4 \pm 2$ for bipolar mania $(\mathrm{n}=13), 12.3 \pm 4.3$ for bipolar depression $(\mathrm{n}=7), 9$ \pm 2.9 for major depressive disorder $(\mathrm{n}=14)$, and $11.2 \pm$ 4.6 for other diagnoses $(\mathrm{n}=3)(\mathrm{F}=2.7, \mathrm{p}=0.027)$.

The number of ECT sessions for elderly patients with MDD (13.4 \pm 4.6$)$ was statistically higher than that for adult patients with $\operatorname{MDD}(9 \pm 2.9)(\mathrm{t}=-2.9, d f=23, \mathrm{p}=0.008)$. There were no significant differences among the patients with other diagnoses (Figure 1). Furthermore, elderly patients with MDD had more severe depressive symptoms than adult patients. For MDD, the baseline mean \pm SD MADRS scores of elderly patients and adult patients were $37 \pm 10.8$ and $28.3 \pm$ 6.8 , respectively $(\mathrm{t}=-2.3, d f=20, \mathrm{p}=0.033)$ (Table 4).

\section{Discussion}

As a result of our study, we found that the mean of the number of ECT sessions was 11.8 (range: 6-24) in remitting psychiatric patients. The number of ECT sessions was 13.3 for individuals with schizophrenia, 10.1 for schizoaffective disorder, 14.4 for bipolar depression, 9.4 for bipolar mania, 10.9 for major depressive disorder, and 11.8 for other diagnoses. Our data were consistent with those of a previous study conducted in Thailand. Specifically, the mean number of ECT sessions was in the same range, although this number was slightly higher in the present study. ${ }^{10}$ This may be explained by our decision to only include inpatients who achieved remission and to exclude patients who stopped ECT treatment earlier, such as those who were unable to tolerate adverse effects of ECT. Patients who could not tolerate adverse effects, especially cognitive decline, tended to stop ECT before achieving remission. However, this number of ECT sessions in the present study was consistent with global figures. ${ }^{19}$

We found that in individuals with MDD, the number of ECT treatments in elderly patients (age $>60$ years) (13.4) was higher than that in adult patients (9). This result is in contrast with previous studies that found older age to be associated with faster remission in MDD patients. ${ }^{7,20,21}$ It is possible that the illness severity in the elderly patients in our study was greater than that in the adult patients (Table 3), and 
- age $<60$ years $\square$ age $\geq 60$ years

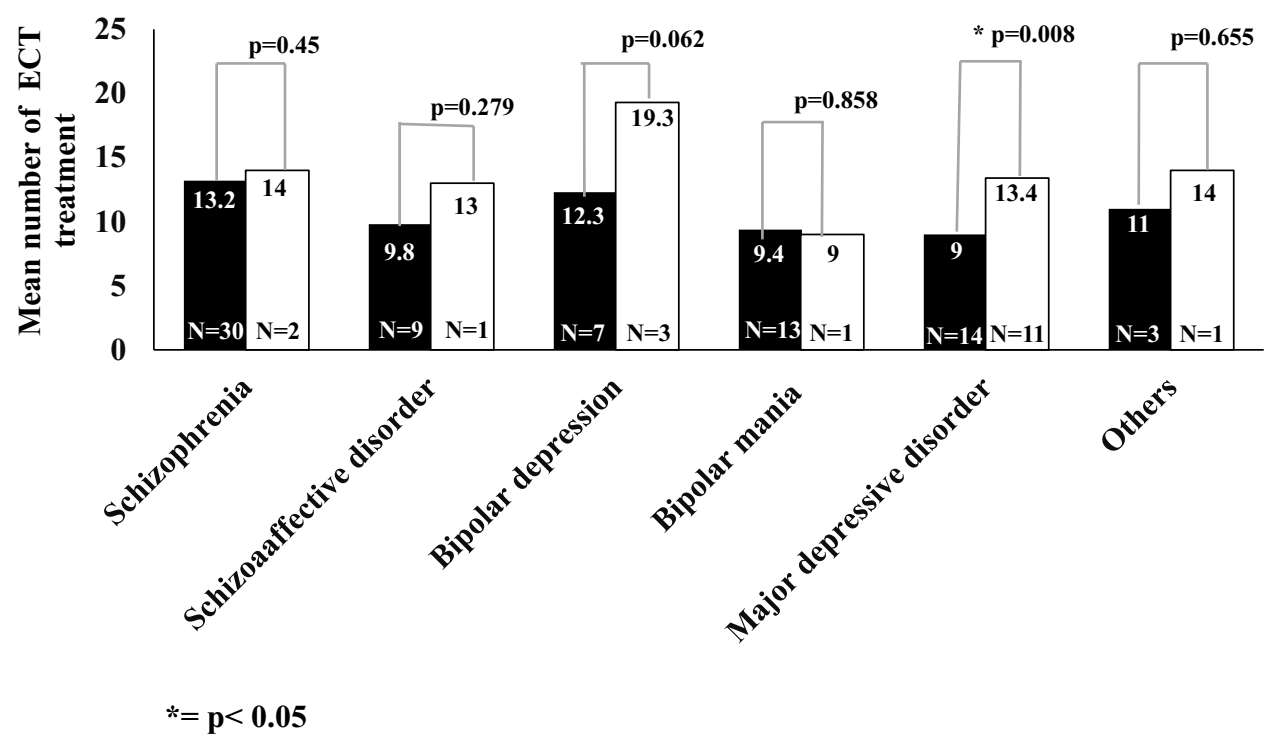

Figure I Number of ECT sessions in elderly vs adult patients by diagnosis ( $\left.{ }^{\mathrm{p}}<0.05\right)$.

thus, that RUL electrode placement was used more frequently in elderly vs adult patients to prevent cognitive adverse effects. RUL electrode placement may have had a weaker effect such that more acute ECT sessions were needed to achieve remission. ${ }^{22}$ Another possible explanation is the potential differences in the course of MDD in adult vs

Table 4 Psychiatric Symptom Scores at Baseline and Post-ECT Treatment

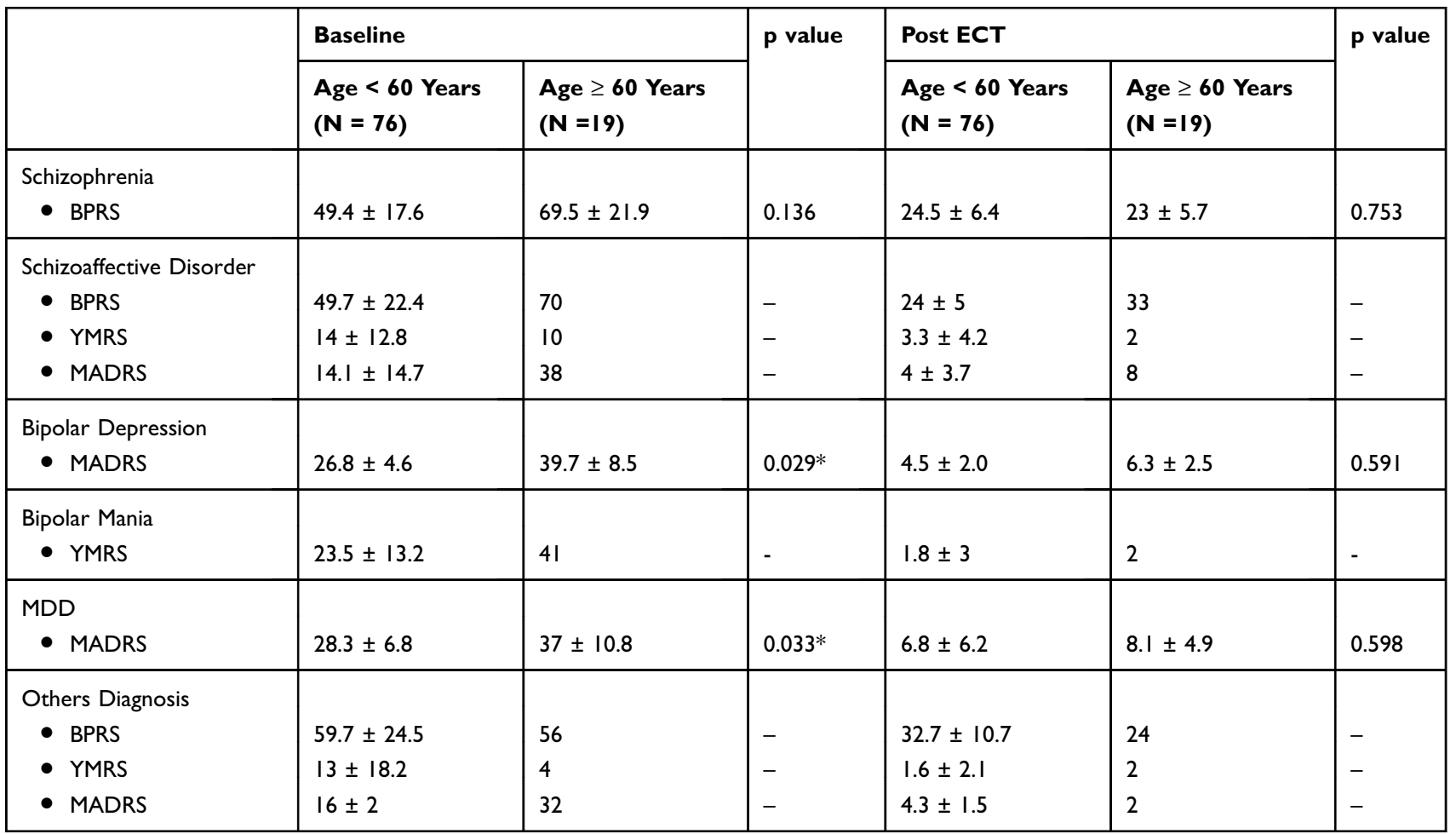

Note: $*_{p}<0.05$

Abbreviations: BPRS, Brief Psychiatric Rating Scale; YMRS, Young Mania Rating Scale; MADRS, Montgomery Asberg Depression Rating Scale; SD, standard deviation. 
elderly patients. A previous naturalistic study demonstrated that the time required to achieve remission in MDD patients increased with age. ${ }^{23}$ Although the difference was not statistically significant $(p=0.062)$, the number of treatments in elderly patients with bipolar depression (19.3) in the present study was larger than that in adult patients (12.3). The lack of significance may have been due to sample size limitations.

A strength of this study was that we explored age and psychiatric diagnosis as factors impacting the number of ECT sessions. However, this study has several limitations. First, the patients were all inpatients at a university hospital in Thailand, so the results should be interpreted with caution in terms of applicability to other settings. Second, other factors that were not identified in the present clinical sample might have influenced the number of ECT sessions (for example, comorbid physical disease and depression subtype). Third, the sample size was small for some of the subgroups, so we may have missed differences between diagnoses. Finally, additional factors that we did not analyze, such as changes in symptoms during ECT, could have influenced the number of ECT sessions. Thus, the influence of these factors may warrant further study.

\section{Conclusion}

We found that the number of ECT sessions varied according to age and diagnosis. The number of ECT sessions in elderly MDD patients was higher than that in adult MDD patients.

\section{Acknowledgments}

Special thanks to staff at the Electroconvulsive Therapy Clinic, Ramathibodi Hospital, for supporting the data collection process. We thank Sydney Koke, MFA, from Edanz Group for editing a draft of this manuscript.

\section{Author Contributions}

All authors contributed to the data analysis, drafting, and revising of the article, gave final approval of the version to be published, and agree to be accountable for all aspects of the work.

\section{Disclosure}

The authors report no conflicts of interest.

\section{References}

1. Mankad MV, Beyer JL, Weiner RD, Krystal AD. Clinical Manual of Electroconvulsive Therapy. Arlington: American Psychiatric Publishing; 2010.

2. American Psychiatric Association. The Practice of Electroconvulsive Therapy: Recommendations for Treatment, Training, and Privileging (A Task Force Report of the American Psychiatric Association). American Psychiatric Association; 2008.

3. Tran DV, Meyer JP, Farber KG, Chen XR, Rosenthal BD, Kellner $\mathrm{CH}$. Rapid response to electroconvulsive therapy: a case report and literature review. $J$ ECT. 2017;33(3):e20-e21. doi:10.1097/YCT.0000000000000408

4. Leiknes KA, LJv S, Høie B. Contemporary use and practice of electroconvulsive therapy worldwide. Brain Behav. 2012;2 (3):283-344. doi:10.1002/brb3.37

5. Agarkar S, Hurt S, Lisanby S, Young RC. ECT use in unipolar and bipolar depression. $J$ ECT. 2012;28(3):e39-40. doi:10.1097/ YCT.0b013e318255a552

6. Daly JJ, Prudic J, Devanand DP, et al. ECT in bipolar and unipolar depression: differences in speed of response. Bipolar Disord. 2001;3 (2):95-104. doi:10.1034/j.1399-5618.2001.030208.x

7. Sienaert P, Vansteelandt K, Demyttenaere K, Peuskens J. Ultra-brief pulse ECT in bipolar and unipolar depressive disorder: differences in speed of response. Bipolar Disord. 2009;11(4):418-424. doi:10.1111/ bdi.2009.11.issue-4

8. Oltedal L, Narr KL, Abbott C, et al. Volume of the human hippocampus and clinical response following electroconvulsive therapy. Biol Psychiatry. 2018;84(8):574-581. doi:10.1016/j.biopsych. 2018.05.017

9. Grover S, Chakrabarti S, Hazari N, Avasthi A. Effectiveness of electroconvulsive therapy in patients with treatment resistant schizophrenia: a retrospective study. Psychiatry Res. 2017;249:349-353. doi:10.1016/j.psychres.2017.01.042

10. Pitidhrammabhorn U, Ittasakul P, Waleeprakhon P, Goldman MB. Clinical characteristics of inpatients undergoing electroconvulsive therapy (ECT) in a university hospital, Thailand. ASEAN J Psychiatry. 2016;17(2):144-150.

11. American Psychiatric Association. Diagnostic and Statistical Manual of Mental Disorders. Text Revision (DSM-IV-TR). 4th ed. Washington: American Psychiatric Association; 2000.

12. Leucht S, Kane JM, Kissling W, Hamann J, Etschel E, Engel R. Clinical implications of brief psychiatric rating scale scores. $\mathrm{Br}$ J Psychiatry. 2018;187(4):366-371. doi:10.1192/bjp.187.4.366

13. Thompson PA, Buckley PF, Meltzer HY. The brief psychiatric rating scale: effect of scaling system on clinical response assessment. J Clin Psychopharmacol. 1994;14(5):344-346. doi:10.1097/00004714199410000-00010

14. Hawley CJ, Gale TM, Sivakumaran T. Defining remission by cut off score on the MADRS: selecting the optimal value. $J$ Affect Disord. 2002;72(2):177-184. doi:10.1016/S0165-0327(01)00451-7

15. Montgomery SA, Asberg M. A new depression scale designed to be sensitive to change. Br J Psychiatry. 1979;134:382-389. doi:10.1192/ bjp.134.4.382

16. Kongsakon R, Bhatanaprabhabhan D. Validity and reliability of the Young Mania rating scale: Thai version. J Med Assoc Thai. 2005;88 (11): 1598-1604.

17. Young RC, Biggs JT, Ziegler VE, Meyer DA. A rating scale for mania: reliability, validity and sensitivity. $B r \quad J$ Psychiatry. 1978;133:429-435. doi:10.1192/bjp.133.5.429

18. Ittasakul P, Likitnukul A, Pitidhrammabhorn U, Waleeprakhon P, Goldman MB. Stimulus intensity determined by dose-titration versus age-based methods in electroconvulsive therapy in Thai patients. Neuropsychiatr Dis Treat. 2019;15:429-434. doi:10.2147/NDT. S187589 
19. Leiknes KA, Schweder LJ-V, Høie B. Contemporary use and practice of electroconvulsive therapy worldwide. Brain Behav. 2012;2 (3):283-344. doi:10.1002/brb3.37

20. Rhebergen D, Huisman A, Bouckaert F, et al. Older age is associated with rapid remission of depression after electroconvulsive therapy: a latent class growth analysis. Am J Geriatr Psychiatry. 2015;23 (3):274-282. doi:10.1016/j.jagp.2014.05.002

21. Rosen BH, Kung S, Lapid MI. Effect of age on psychiatric rehospitalization rates after electroconvulsive therapy for patients with depression. $J$ ECT. 2016;32(2):93-98. doi:10.1097/YCT.000000 0000000271
22. Sackeim HA, Prudic J, Devanand DP, et al. A prospective, randomized, double-blind comparison of bilateral and right unilateral electroconvulsive therapy at different stimulus intensities. Arch Gen Psychiatry. 2000;57(5):425-434. doi:10.1001/archpsyc.57. 5.425

23. Schaakxs R, Comijs HC, Lamers F, Kok RM, Beekman ATF, Penninx B. Associations between age and the course of major depressive disorder: a 2-year longitudinal cohort study. Lancet Psychiatry. 2018;5(7):581-590. doi:10.1016/S2215-0366(18)30166-4

\section{Publish your work in this journal}

Neuropsychiatric Disease and Treatment is an international, peerreviewed journal of clinical therapeutics and pharmacology focusing on concise rapid reporting of clinical or pre-clinical studies on a range of neuropsychiatric and neurological disorders. This journal is indexed on PubMed Central, the 'PsycINFO' database and CAS, and is the official journal of The International Neuropsychiatric Association (INA). The manuscript management system is completely online and includes a very quick and fair peer-review system, which is all easy to use. Visit http://www.dovepress.com/testimonials.php to read real quotes from published authors. 